\title{
Grassroots Developmental Imprints Through Electrical Energy Production and Distribution in Kururu, Cameroon
}

\author{
Tende Renz Tichafogwe ${ }^{1,}$, Ndzie Souga Clotaire², Woregwe Emmerencia Edam² \\ ${ }^{1}$ Department of Geography, Faculty of Arts, Letters and Social Sciences, the University of Yaounde 1, Yaounde, Cameroon \\ ${ }^{2}$ Department of Geography, Higher Teachers' Training College, the University of Yaounde 1, Yaounde, Cameroon \\ Email address: \\ renztende@yahoo.com (T. R. Tichafogwe), clotario1980@yahoo.fr (N. S. Clotaire), worendam@gmail.com (W. E. Edam) \\ ${ }^{*}$ Corresponding author
}

\section{To cite this article:}

Tende Renz Tichafogwe, Ndzie Souga Clotaire, Woregwe Emmerencia Edam. Grassroots Developmental Imprints Through Electrical Energy Production and Distribution in Kururu, Cameroon. Landscape Architecture and Regional Planning. Vol. 3, No. 3, 2018 , pp. 64-71. doi: 10.11648/j.larp.20180303.11

Received: July 15, 2018; Accepted: August 1, 2018; Published: August 29, 2018

\begin{abstract}
Significant quantities of Energy Resources in Sub-Saharan Africa are still unexploited due to derisory technological savoir faire and funding. Close to $75 \%$ of Cameroon's electric power is obtained from hydropower schemes while the rest comes from other renewable energy sources. Despite these vast energy potentials, access to, and distribution of, electrical energy is a herculean task, especially in rural areas. Faced with acute electricity shortages and unreliable supply, the people of the Kururu village have sought for a means to produce and distribute local electrical energy. This article x-rays the strategies put in place by the local community to salvage their inadequate electricity supply. The paper advocates that local communities can synergize to develop their areas. Data collection in the Kururu village was done through the administration of questionnaires, field observation and focus group discussions. Also, 483 inhabitants of the Kururu village representing a $20 \%$ sample were questioned. A total of 53 households were administered questionnaires from the 265 households which make up the entire population. Results from findings revealed that a $9 \mathrm{~m} 2$ surface area and $1.7 \mathrm{~m}$ deep dam was constructed to generate some 25 to $30 \mathrm{KW}$ of electricity. This enabled six out of eight neighbourhoods of the Kururu village to be electrified through two distribution centres. Some $67 \%$ of funds for the electricity project were supplied by the ADEID non-governmental organization, $22 \%$ from the local community and $11 \%$ from the village development associations. The presence of electricity has led to the establishment of businesses which have enhanced socio-economic development in the area. Accessibility to electricity has also upgraded the learning process in the area and abridged the rate of rural exodus. This paper endorses that four additional electricity distribution centres be created, in order to reduce the shortages of electricity and ensure a steady supply in all the quarters of Kururu.
\end{abstract}

Keywords: Grassroots, Electrical Energy, Local Community Initiative, Electricity Distribution, Kururu Village

\section{Introduction}

Energy Resources such as solar energy, hydroelectric power, wind and geothermal energy in Sub-Saharan Africa are more than sufficient to meet local, regional and national needs. However, most of these resources have not been fully surveyed or discovered due to inadequate technology as far as the exploitation of energy is concerned [1]. This has increased the reliance on the hydropower potential which is still not fully tapped, due to inadequate survey and exploitation.
In Cameroon, a majority of the country's population still depends on conventional solid fuels such as charcoal for cooking and other household uses such as lightning. Close to $75 \%$ of the Cameroon's electric power is obtained from hydropower schemes with the other $25 \%$ from renewable energy sources [2]. There are three major hydroelectric power stations in Cameroon. These are the Song-Loulou generating $388 \mathrm{MW}$ of electricity supply, Edea with $262 \mathrm{MW}$, and Lagdo for its part, generating 72MW of electricity supply [3]. More plants such as the Lom Pangar storage dam aim to supply $170 \mathrm{MW}$ of electrical energy, the development of hydroelectric schemes at Nachtigal with $280 \mathrm{MW}$, as well as 
that of the Memve'ele to supply 200MW. They are still under construction and their completion will raise the capacity of the plants by $75 \mathrm{MW}[3]$.

Despite Cameroon's huge hydro energy potentials, access to electrical energy still remains a problem, given that only $48 \%$ of the total population has access to electricity with most of it concentrated in the urban spaces. Recent statistics on energy distribution reveal that $90 \%$ of urban households are electrified unlike $23 \%$ of rural households [4]. Moreover, the high rate of access to electricity in urban spaces have caused regional and socio-economic disparities. Recent studies have further revealed that $35 \%$ of poor urban households and $88 \%$ of poor rural households do not have access to electricity [4]. This signifies that the poorest strata in both the urban and rural areas constitute the most disadvantaged groups. The regions that suffer the most from the lack of electricity supply are mainly those with large rural concentrations such as the Adamawa, East, Extreme North, North, North West, and South West regions. The average rate of electricity access in these regions is $10 \%$ with the less privileged class and 33\% with the privileged class [3].

Access to electricity supply is a key determinant to development. Hydroelectricity can be produced from many sources such as streams, rivers, and lakes. Most regions, especially the North West region, find it very difficult to generate electricity and thus are only reception centres. The inability to develop these potentials causes the North West
Region to remain a reception centre of electricity that is produced elsewhere in Cameroon. This explains why in remote and enclaved areas of the North West Region, people still depend on bush lamps and generators despite the expensive running costs. Faced with such difficulties, the Kuruku community decided to generate its own electricity with the help of a non-Governmental Organization, by exploiting the available natural potential of their area.

This paper, which is centered on a micro hydroelectricity scheme, explores ways in which the local population exploits their natural potentials in order to satisfy their needs while remaining environmentally friendly. The local initiative put in place by the population of Kuruku with the support of Action Pour un Développement Equitable Intégré et Durable (ADEID) non-Governmental Organisation, has led to the generation and distribution of electricity in the area. This paper shows the role played by the local population in the electrification of enclaved areas.

Kuruku is found in Batibo Sub Division of Momo Division in North West Region of Cameroon. It is located between latitude $5^{0}, 40$ and $5^{0} .47$ North of the equator and longitude 9.45 and 9.48 East of the Greenwich meridian. It is bounded to the North by Ewoh and Tiben, to the South East by Krugwe, to the East by Angie and to the west by Elum and Diche II villages (Figure 1). Kuruku village has a relatively hilly relief and the altitude ranges from 960 to $1217 \mathrm{~m}$. The village has a total population of 483 inhabitants [5].

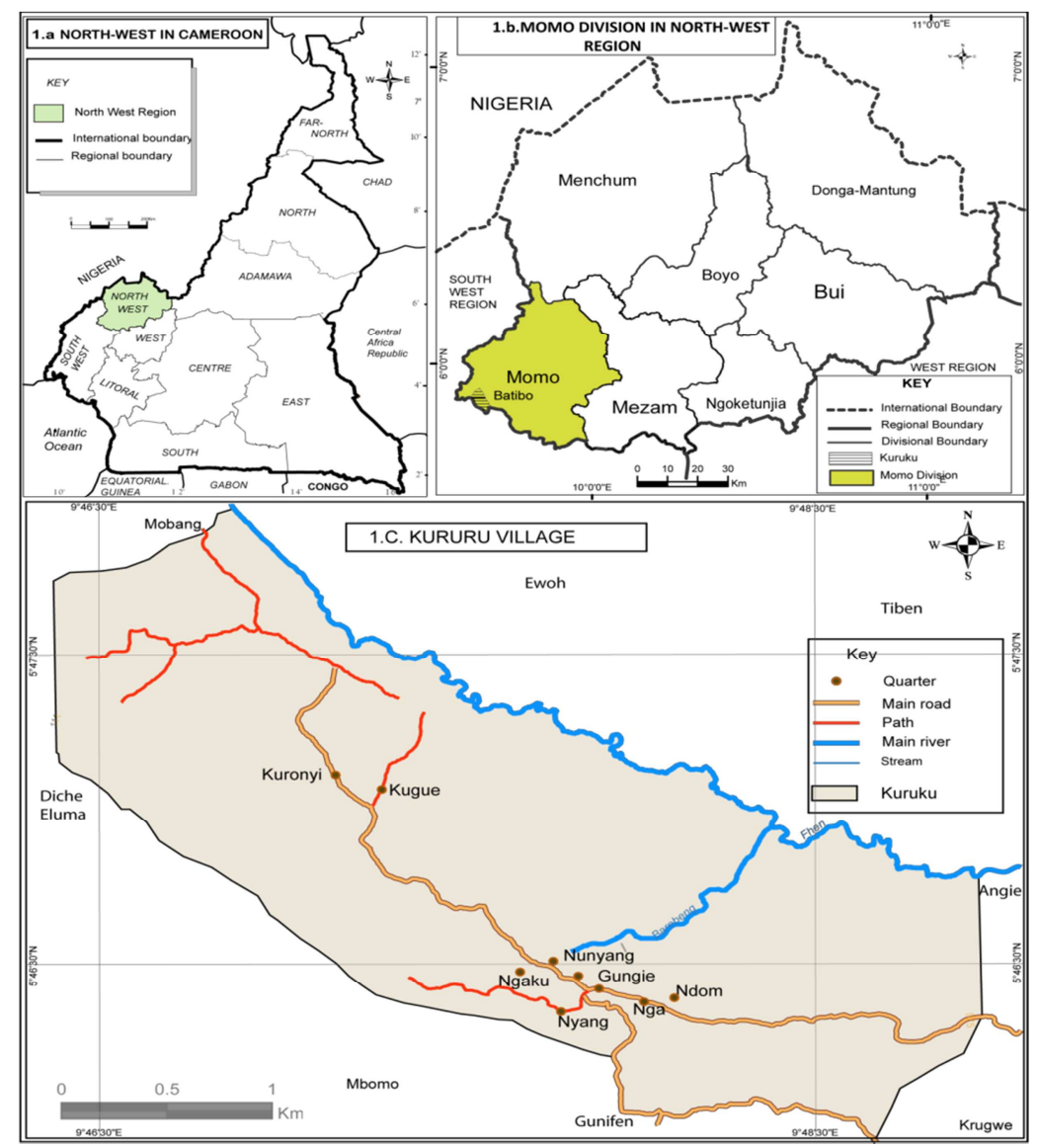

Source: Adapted from the National Institute of Cartography Cameroon, 2018

Figure 1. The Kururu Village in the North West Region of Cameroon. 


\section{Methodology}

Data collection in the Kururu village was done through the administration of questionnaires, field observation and focus group discussions. Also, 483 inhabitants of the Kururu village, representing a $20 \%$ sample, were questioned. A total of 53 households were administered questionnaires out of the 265 households of the Kururu population [5]. Therefore to arrive at the 53 households, the total number of households were multiplied by 20 and divided by 100 (20 X 65/ 100= 53). Field observations on the various households in the Kururu village revealed that an acute problem, which is the absence of electricity, was noted in the area. The observations permitted the understanding that the micro hydroelectricity project of Kururu was jointly put in place by the local population and ADEID, a non-Governmental Organisation.

Focus group discussions were done with the project managers, electricity users and small business operators such as retailers, phone boot operators, barbers and hair dressers. This permitted the detailed understanding of the project and how it will benefit the inhabitants of the village. All data collected from the various sources were treated to generate results.

\section{Results and Discussion}

Results from findings revealed that the success of the Kururu micro hydroelectricity project was jointly put in place by the local population and the non-Governmental Organisation Action Pour un Développement Equitable Intégré et Durable (ADEID), which improved on the development of the area.

\subsection{Local Population Impact on the Production and Distribution of Electricity in Kururu}

Kururu before the implantation of hydroelectricity had never benefited from any electricity supply from Energy of Cameroon (ENEO). The inhabitants therefore sought for selfreliant development and thought it wise to generate their own electricity by exploiting the available natural potential in the area. Before the implantation of the micro hydroelectricity project (HEP) scheme in Kuruku, different sources of lighting such as bush lamps, candles, torches, lamps, stoves and generators were used. Most of these sources were mainly used for lighting with fuel from wood considered as the most commonly used one. These sources of lighting could not provide adequate energy supply that could be used by business and household needs. Faced with such difficulties, the local population took upon themselves to find a solution.

The Kuruku Development Association (KUDA) and Kuruku Youth Association (KYA) conceived and lunched a fund raising towards the Kuruku micro hydroelectricity project in collaboration with the local population. This amounted to about 4 million FCFA. All indigenes both at home and abroad were levied certain amounts of money as contributions. These amounts of money ranged from 15,000 FCFA to 100,000 FCFA, depending on the financial strength of the individual. Nevertheless, estimates for the construction of a dam to generate the electricity stood at 14million CFA, according to the ADEID. With such estimates, fund raising exercises which were organized by the village development associations were doubled every year from 2010 to 2016. These improved efforts enabled the Kururu village community to raise an additional 4 million FCFA which was completed by the ADEID to realize the electricity project.

It is interesting to note that, self-reliance in community development has always been a tool used to transform many local communities that feel abandoned by the State [6]. As argued by Fonchingong and Fonjweng in (The concept of Self-reliance in Community Development Initiative in the Cameroon Grassfields. Nordic Journal of African Studies, 12 (2): 196-219, The University of Buea, 16p), this concept has helped the people of Kururu as well. The people of Kuruku through self-reliant development have greatly sacrificed through financial contributions, community assistance and technological services to ensure the putting in place of the Kuruku micro hydroelectricity plant. Field revelations explain how that the local population reduced their farming days from 6 days to 3 days a week in order to ensure that this micro hydroelectricity project be put in place. Such huge sacrifices could only lead to a successful electricity supply in the area. Their financial and material assistance was greatly felt in the construction of the dam.

\subsection{The Construction of the Kuruku Dam for Electricity Generation}

The construction of the dam by ADEID started in 2011 and ended in 2014. The Kuruku community was sensitized through the village council to provide the necessary labour for the putting in place of the scheme. This was often done on "off days" commonly known as "country Sundays". Since the day set aside was insufficient to hasten the construction process, the local community increased the assistance days to three. The construction process proceeded with material assistance from the people as well as food and drinks during recreational periods. Accommodation of the NGO's technicians was given by some selected people of the Kururu village and the work went on smoothly among the parties concerned. The provision of food and drinks by the local population of Kuruku during the construction phase provided the workers with much strength that enabled them to work for longer periods in order to complete the project.

The Kuruku dam has a surface area of about of $10 \mathrm{~m}^{2}$ and an average depth of $1.7 \mathrm{~m}$. This dimension was what the financial strength of the local community could carry, including the available water supply even during dry periods. Materials such as concrete, stones, iron rods, cement, planks and sand were used in constructing the dam. The mixture of cement, sand and concrete facilitated the putting in place of a solid wall to withhold water in the dam. The construction of the dam took place in January, which is the dry season since 
the water volume of the Barebeng stream, which was used at this period, is usually at its lowest level. As such, it could easily be diverted. Upon completion of the dam, the stream channel was re-directed to follow its normal course and the dam filled with water as a reserve to produce hydroelectricity (Figure 2).

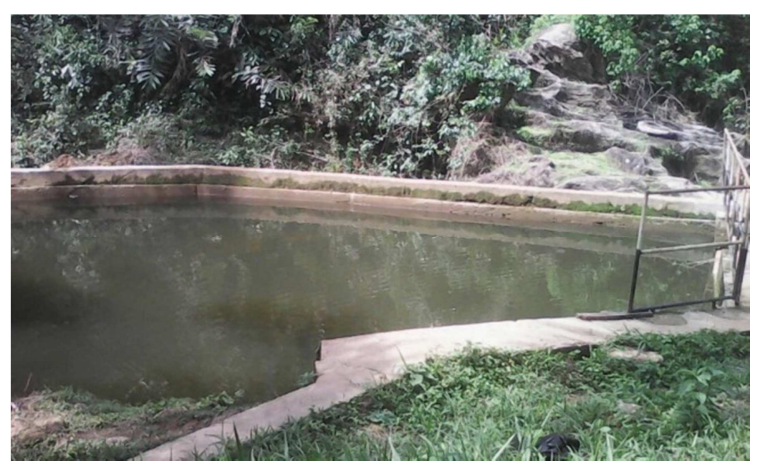

Woregwe, 2017

Figure 2. The Kururu Micro Hydroelectricity Project.

Figure 2 exhibits the Kururu Dam some three years after its effective construction. It is worth noting that, the size of the dam is too small $\left(10 \mathrm{~m}^{2}\right)$ to contain water, especially during the wet season. Field revelations showed that during the dry season, especially in the months of January to February, the water level usually drops to an average depth of 1.1 metres and can barely provide enough water for the spinning of the turbine, thus affecting the quality of the scheme.

Hydroelectricity production necessitates some basic materials such as pipes, cables, turbines, generators and poles in order to be properly installed [7]. With help from financial contributions made by the local population, these materials were provided to facilitate electricity distribution in Kururu. After the construction of the Kururu dam, water was directed through cemented gutters to the septic tanks. Pipes were then used from the septic tank to tap water to the turbines. The diameter of the pipes was selected because they were used to increase the pressure at which the water runs through them. The energy contained in running water is transformed to electrical energy through a generator. This was then used to generate electricity of about $20-30 \mathrm{KW}$ a day. Even though the dam was initially envisaged to generate some $30 \mathrm{KW}$ of electricity daily, some discrepancies occurred along the line. The cemented gutter was constructed without a slant as well as the presence of bends on the pipeline, which reduced the quantity of electrical energy produced by the scheme. However, despite these flaws, the people of Kuruku could still benefit from electricity production and distribution.

\subsection{The Role of ADEID in the Electrification of Kururu}

The realisation of the Kururu hydroelectricity micro project was a success because of the technical, material and financial support of the ADEID. This organisation, which was established in Cameroon in the 1990s, is geared towards the provision of sustainable solutions to the problem faced by people fighting against poverty. The ADEID has installed micro hydroelectricity schemes in remote areas of Cameroon and other African countries. ADEID offers different types of assistance such as technical support, project monitoring, evaluation as well as research for possible technical sources. When the people of Kururu expressed the need for support in the electrification of their area, ADEID sent its environmental experts who carried out feasibility studies on the Barebeng stream and river Fhen.

The results of the feasibility studies led to the selection of the Barebeng stream for the micro project and the provision of technicians for the construction of the dam and the distribution of electricity. ADEID also assisted the local population in the payment of materials used in the construction of the dam even though the bulk of the funds were provided by the local population. Consistent monitoring of the project in the course of the construction through checks of the efficient work done by technicians was being carried out. Two local project managers were trained to take care of any repairs that could occur along the line. These mangers had the duty of regulating the step-up transformer in the electricity supply process.

Field exchanges with the project manager showed that high voltage occurs during the rainy season. The manager has the duty of regulating the voltage between the ranges of $220 \mathrm{~V}-240 \mathrm{~V}$ to make it stable. In this way the constant supply of electricity will remain stable and the population will have little to complain about. Results from findings revealed that $67 \%$ of the funds for the micro electricity scheme in Kururu came from the ADEID. The local community put in $22 \%$ and the village development associations put in place $11 \%$. However, the completion of the project was a collective effort of all parties. The local community was able to galvanize their efforts because of available potentials. It is worth nothing that a majority of Sub-Saharan African countries have enormous unexploited energy potentials [8]. Such is the case of Cameroon in general, and the Kururu village in particular. The huge efforts of ADEID let to the generation and distribution of electricity in Kururu.

\subsection{The Generation and Distribution of Electricity in Kururu}

The generation and distribution process of electricity in Kururu involved the transmission of the electricity from the power house to the population. The Kuruku electricity micro project uses a small dam to generate hydroelectricity. Water from the dam is directed to the septic tank through a cemented gutter that is some $25 \mathrm{~m}$ away from the dam. The septic tank, which is $2.5 \mathrm{~m}$ wide, serves as a water reservoir. Water is then transported from the septic tank through galvanized pipes and plastic pipes supported with pillars. The water that runs through the pipeline to the power house is used to turn the turbines with the help of a pulley which spins the generator and produces electricity. The turbine, generator and the step up transformer are installed in the power house (Figure 3). Field discoveries showed that the quantity and quality of energy produced is determined by the force contained in running water which turns the turbine. Electricity that is produced by the generator is 
transported with cables to the step-up transformer where other adjustments are made to improve on the quality of electricity distributed. The transmission of the electricity produced is from the power house to the step-down transformer. The Kururu micro hydroelectricity scheme has a step-up transformer which produces 250 volts of electricity. This electricity supply oscillates with seasons, between 140 volts to 170 volts in the dry season and 210 volts to 250 volts in the wet season.
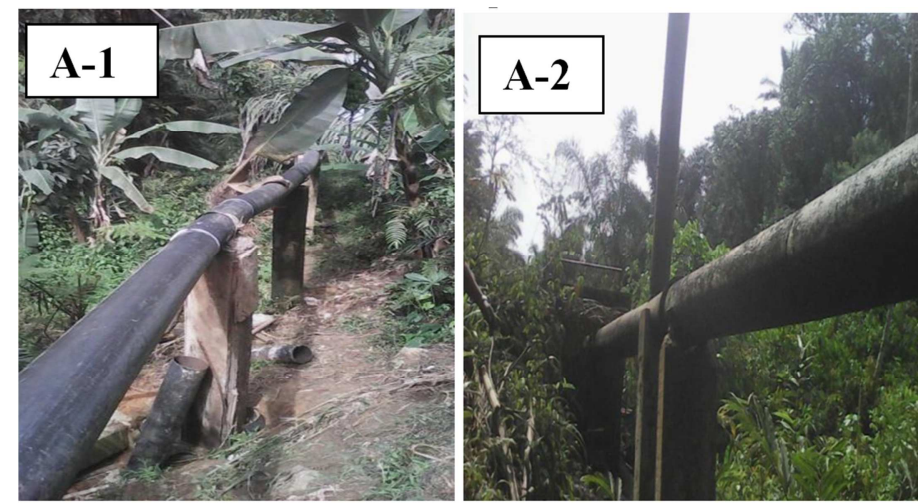

Woregwe, 2017

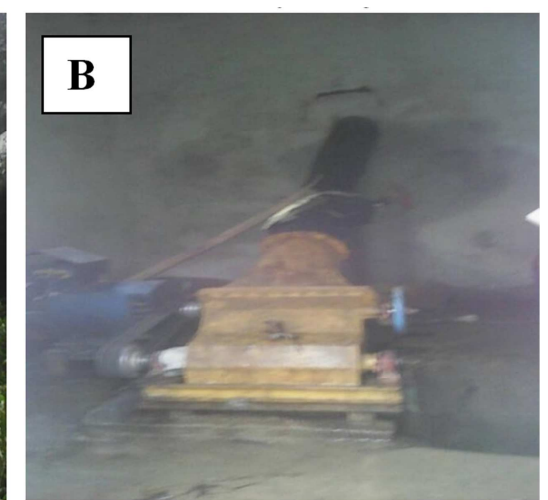

Figure 3. The Pipeline and Turbine of the Kururu Electricity Project.

Figure 3 shows samples of the plastic pipe in A-1, and the galvanized pipe in A-2, as well as the turbine in B which helps in spinning the generator.

Such fluctuations in the supply of electricity are the major course of the damages suffered by household appliances. Since the Kururu village does not have a step-down transformer, it is difficult to resolve the problem of electricity shortage and discrepancies in the supply. Nevertheless, in the transmission process, electricity from the power house is then transferred through cables to various quarters of the Kururu village. Insulators were also used in the transmission of electricity in order to protect the cables from being destroyed by any rough surface, and to facilitate the flow of electricity. High surfaces were preferred to low ones in the transmission process in order to avoid obstructions from trees, and other tall vehicles. Also, tall electricity poles were preferred to shorter ones in order to prevent any risk of electrocution of the inhabitants of the Kururu village. All these processes were applied to carry the electricity to the local population. Some $25 \mathrm{KW}$ of electricity was generated daily and distributed to the local population (Table 1).

Table 1. The Distribution of Electricity in Kururu.

\begin{tabular}{lll}
\hline Quarter & Daily electricity consumption/KW & Percentages \\
\hline Ngaku & 5.2 & 20.8 \\
Ndom & 4.9 & 19.6 \\
Gungie & 3.8 & 15.2 \\
Nyang & 3.9 & 15.6 \\
Nga & 3.5 & 14 \\
Nunyang & 3.7 & 14.8 \\
Kuronyi & 0 & 0 \\
Kugue & 0 & 0 \\
Total & $25 \mathrm{KW}$ & 100 \\
\hline
\end{tabular}

Source: Kururu Local Council, ADEID NGO, Field Work, 2017

Despite the generation of $25 \mathrm{KW}$ of electricity by the Kururu project, some quarters did not benefit from it because they could not be reached. The Ngaku quarter, which is the headquarters of the village, has $20.8 \%$ daily consumption, while Nga has $14 \%$ as well. However, six out of eight villages benefited from the electricity supply, which is a dream come true for the village.

\subsection{The New Kururu After the Supply of Electricity}

Electricity generation and distribution in Kururu is one of the most important developmental projects that have changed the lives of the people. The distribution of electricity in this area was without discrimination since, it was for the benefit of the entire village. From the eight neighbourhoods which make up the Kururu village (Ngaku, Nyang, Nga, Gungie, Kugue, Ndom, Nunyang and Kuronyi), six benefited from electricity supply while two (kugue and kuronyi) did not (Figure 4). These two neighborhoods were too far from the Kururu micro electricity plant and their connection costs were more expensive than that of the other quarters. Since the construction and distribution budget could not permit the project to supply electricity to every individual at the time, further plans were made to ameliorate the situation of the other two neighborhoods in the nearest future. 


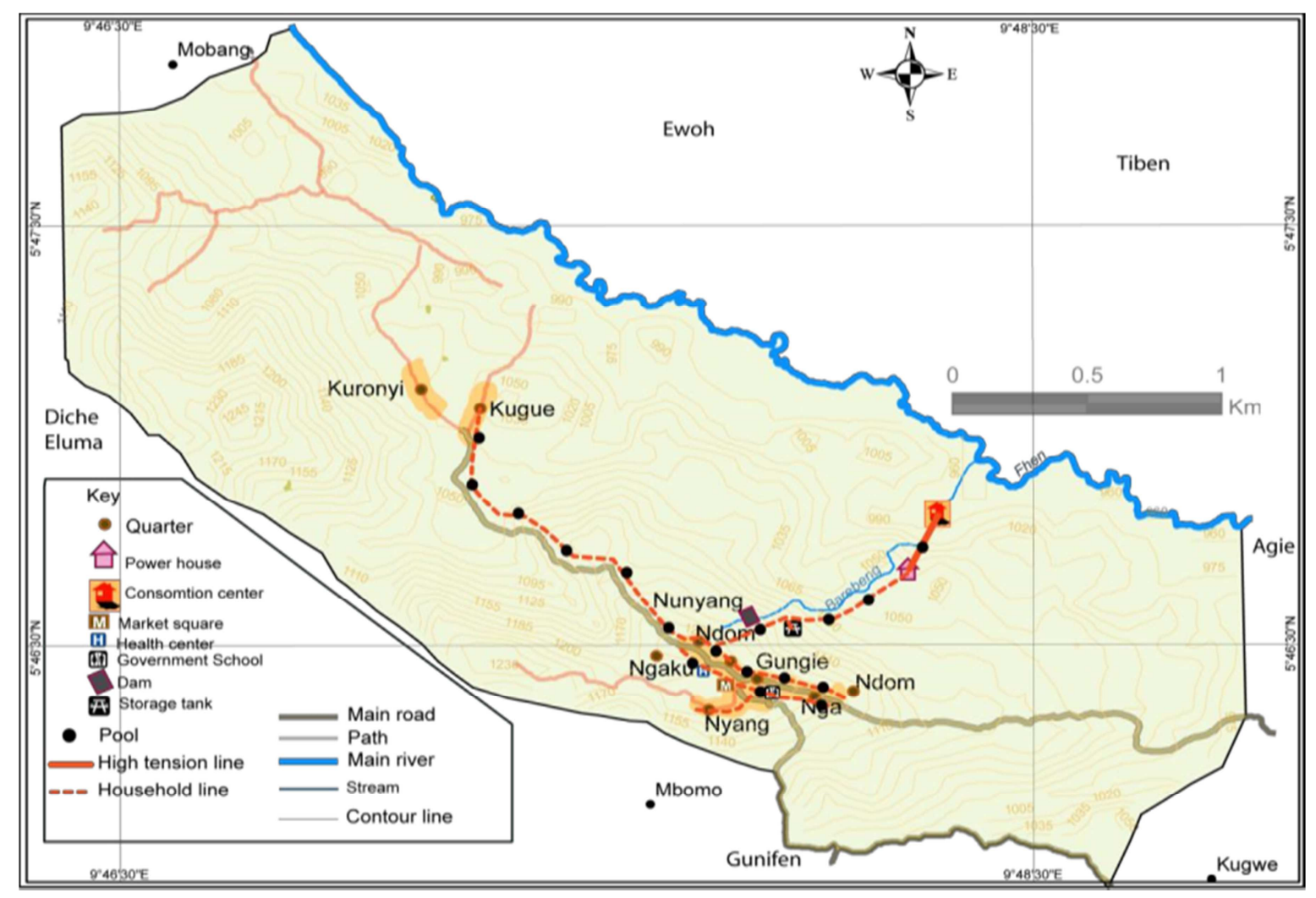

Source: National Institute of Cartography, Cameroon, 2016 and Field work, 2017

Figure 4. The Kururu Micro Hydroelectricity Network.

The distribution of electricity in Kururu was done on a single current line with two cables. All households took their connections from this single line which ran from one quarter to the other. In order to minimize consumption and reduce voltage fluctuations in electricity supply, the consumers of Kururu were advised to use 7 watts bulbs and not 25 to 100 watts bulbs because they consume less electricity. The original six distribution centres envisaged for the project could not be constructed from the limited funds. This made the area to function with only one distribution centre with the various flaws it created along the line. The electricity users experienced high voltage supply especially during the wet season which damages their appliances. There is also limited supply during the dry season. That notwithstanding, close to $75 \%$ of the local population of Kururu can now boast of electricity supply. These on-the-spot strategies were developed in order to maintain a sustainable development in the area [9]. This will enable local communities to exploit and use their energy resources to develop their areas.

\subsection{The Local Developmental Benefit of the Kururu Micro Hydroelectricity Project}

The generation and distribution of electricity in Kururu has influenced the social, economic and environmental development of the area. From a social perspective, the availability of electricity in Kururu has eased the learning process in the area. Students and pupils are now able to continue the learning process at home after school which was not the case before. More than $90 \%$ of students discussed with could testify to the advantages electricity has brought to their studies. Instead of their regular farm work after school, they can now have time to study. The use of bush lamps which were strenuous to study with as a result of poor lighting, to inadequate kerosene supply, have been replaced by electricity. The rate of rural exodus in the Kururu village has equally dropped due to available electricity. The dire need for social amenities such as water and electricity, which were absent in the village before the project, has now been met. This has made the youths who could not live in the village before to stay put. The supply of electricity has therefore helped to reduce rural to urban migration in the village.

The generation of electricity by the Kuruku micro hydroelectricity has transformed the area into a touristic site. The scheme has drawn the attention of tourists from different countries that come in to discover the area. Goodwill donations are also received from tourists who visit the site. These donations serve as a source of revenue to the scheme. Furthermore, the visit of tourists permits the local farmers to sell some of their farm products and other works of arts. This helps to generate revenue for them and their families to survive. The availability of electricity has made micro enterprises such as bars, retail shops, barber's shops and grinding mills to start operating in the area. This renders life easier for its inhabitants. Technological innovations, especially in the energy sector, can now come to the limelight 
from the Kururu scheme. Electricity generated from the Kuruku micro hydroelectricity scheme is cheap and hence, affordable. The electricity project has been perceived as a means through which remote and enclaved rural areas in Cameroon in general and Batibo in particular, can benefit from electricity supply. This has improved on the development of the national energy efficiency policy and strategy for Cameroon which is now a course for concern [10].

The Kururu electricity scheme has also improved on the environmental development of the area. The size of the dam, which is $10 \mathrm{~m}^{2}$, makes it environmentally friendly since the amount of energy produced by a scheme is determined by the size of the dam [3]. The dam is shaded with raffia palms which protects it from direct sun rays and prevents a high rate of evaporation as is the case with dams in an open environment. The Kururu electricity scheme is lucky to operate with a renewable source of energy. Since the scheme uses the energy contained in running water to produce electricity, the water course is continuously replenished through rainfall making it available at all times. Renewable energy sources are those whose quantity do not diminish in the course of exploitation, but are continuously replenished with time. The Kururu electricity scheme has encouraged many establishments to operate in the area and thus has resulted to the development of the locality.

\subsection{Futurist Amelioration for a Complete Supply of Electricity to the Entire Kururu}

The generation and distribution of electricity in Kururu did not satisfy the entire village. This is because the micro hydroelectricity project experienced some discrepancies. In the first place, the envisaged six distribution centres of electricity after generation were not constructed due to limited funds. This made the lone distribution centre to find it difficult to supply electricity to all the quarters of the village. Thus, out of the eight quarters that make up the Kururu village, six benefited from electricity while two (Kuronyi and Kugue), remained without supply despite their financial support.

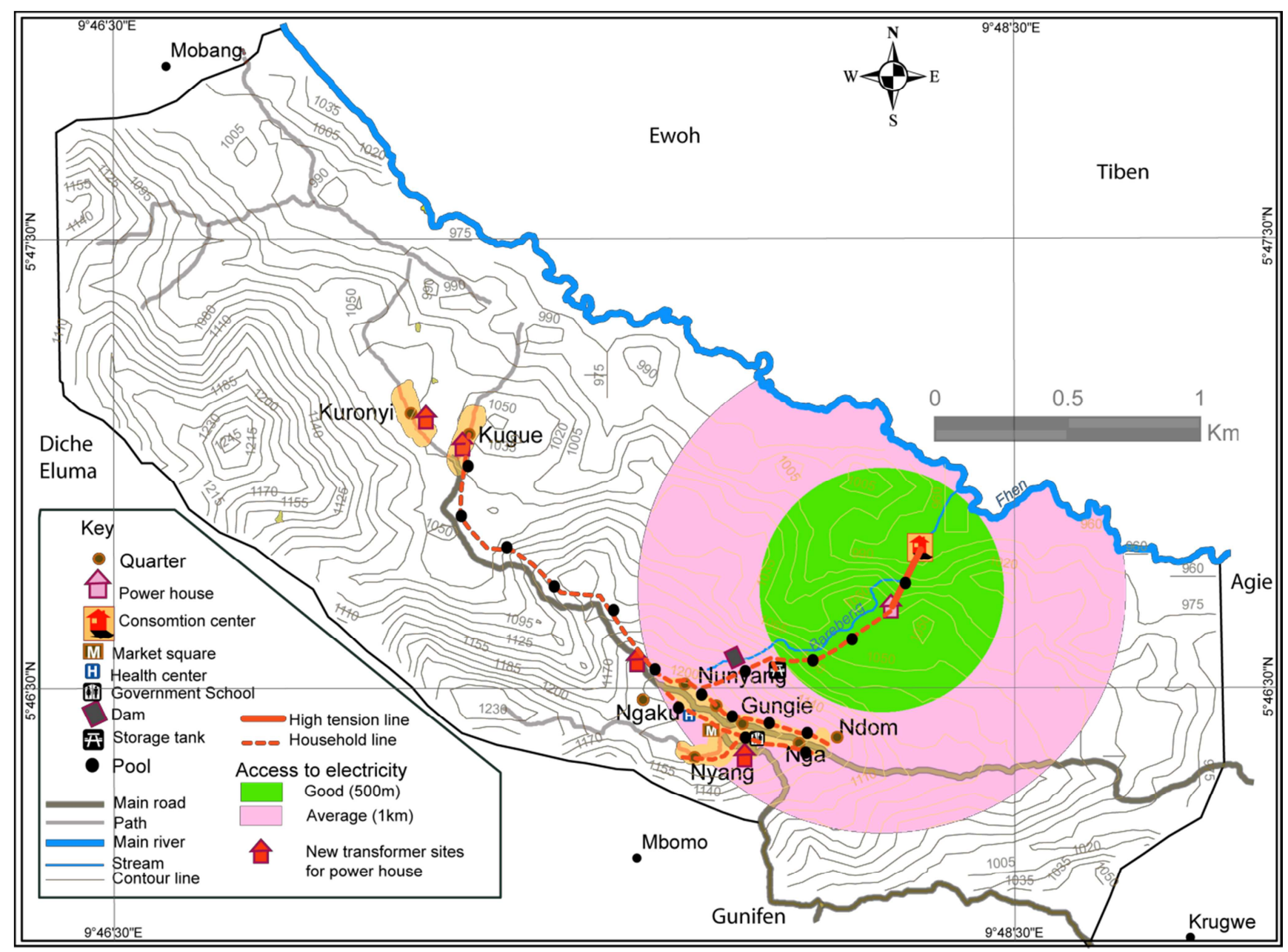

Source: ADEID, Kururu Local Council, NIC and Field work, 2017

Figure 5. The Futurist Electricity Network in Kururu.

Furthermore, a step-down transformer, which was to be used to regulate energy fluctuations, could not be purchased as a result of inadequate funds. This made the area to experience voltage problems, especially during the dry 
season, leading to the damage of household appliances and other materials. The production capacity of the dam posed a problem since it could not permit the generation of more than $30 \mathrm{KW}$ of electricity. Hence, any attempt to supply more than the expected voltage would damage the system. The Kuronyi and Kugue quarters of the Kururu village could not benefit from electricity supply due to their long distance away from the lone distribution centre. Also, the pipeline as well was attacked by corrosion and faced a shortage due to limited funds.

Faced with such flaws, the Kururu electricity generation and supply could not have registered a hundred percent success, nor satisfied the villagers $100 \%$. However, this paper found out that some readjustments could be made on the scheme in order to permit maximum supply of electricity to the entire village. In this vein, the six proposed distribution centres ought to be constructed in order to regulate and distribute electricity to all the quarters of the village. In addition, a step-down transformer is imperative in order to regulate voltage fluctuations, preserve the lives of the inhabitants and protect their appliances from being damaged. Such changes will render an improvement in the scheme and permit all the quartets of Kururu to benefit from electricity supply (Figure 5).

Figure 5 shows a proposed electricity network of the Kururu village with improved distribution. New transformer sites for the power houses are to be constructed in order to receive energy from the main one and regulate it before distribution. The new network will have six distribution centres to curb the problem of high voltage and ameliorate electricity distribution. This will improve on the quality of electricity produced in Kururu and will permit some neighbouring villages such as Mobang and Elum to benefit from the scheme as well.

\section{Conclusion}

The Kururu Micro Hydroelectricity Project was successful from the collective efforts of the ADEID NGO, the Local Development Associations KUDA and KYA, as well as the local population. The objective of this paper was to show that grassroots initiative in the development of a locality became successful in Kururu through local electricity generation and supply. The concept of self-reliance is set to have stood the test of time in Kururu since the local population worked indefatigably to see their dream come true. Businesses, schools and other leisure activities are now operating continuously from electricity supply. This paper found out that electricity generation and supply in the Kururu locality was more than $75 \%$ satisfactory. The study noted that despite some flaws which could not permit every quarter of the village to benefit from electricity supply, some improvements and ameliorative strategies were proposed, which if taken into consideration, will curb the existing discrepancies.

\section{References}

[1] Energy Literacy. (2012). Essential Principles and Fundamental Concepts for Energy Education U.S. Department of Energy, 1000 Independence Ave SW Washington DC, 20585, 202586-5000. Article at

http://www.eere.enrgy.gov/education/energy-literacy.html, accessed November 2017.

[2] Bobbo Tansi, N. (2014). Assessment of Cameroon's Renewable Energy Resource Potential and Prospects for a Sustainable Energy Development. Branding, University of Technology Cottbus, 98p.

[3] Lighting Africa. (2012). "Lighting Africa Policy Report NoteCameroon", 2012, IFC and WB, 114p.

[4] Asa Nvernyuy, W and Saah Ndifon. (2015). Renewable Energy Potentials in Cameroon, Prospects and Challenges, Edition Cle, 207p.

[5] BUCREP. (2010), "National Population and Housing Census of Cameroon of 1976, 1987, 2005", Cameroon Census Office, Cameroon, December 2005 and 2010 Projections, 567p.

[6] Fonchingong Charles and Fonjweng Lordsman. (2010). The concept of Self-reliance in Community Development Initiative in the Cameroon Grassfields. Nordic Journal of African Studies, 12 (2): 196-219, The University of Buea, 16p.

[7] World Energy Outlook. (2014). Africa Energy Outlook: A Focus on Energy Prospects in Sub-Saharan Africa, Paris, France, 283p.

[8] Arthouros Zervos. (2016). Renewable Energy Potentials Network for the $21^{\text {st }}$ Century, 251p.

[9] International Energy Agency (IEA). (2002). Harnessing Energy Resources for Sustainable Development in Africa $p$ 36: IRENA Analysis Based on IEA: World Energy Outlook 2012; UN: World Population Prospects 2010 Revision.

[10] EUEI-PDF and ARSEL. (2013). "Development of a National Energy Efficiency Policy, Strategy and Action Plan in Cameroon - Inception Report", 2013, 209p. 